\title{
Hidden Reading Problems in ESL Learners
}

Paul Meara, Max Coltheart, Jackie Masterson

This article reports a case of a native speaker of Spanish who has severe reading and spelling difficulties in English. These difficulties resemble those found in surface dyslexia. It is argued that he also has the same difficulties in Spanish, but the regular spelling system of Spanish prevented his difficulties from becoming apparent. We consider the possibility that the writing system of a speaker's $\mathrm{L} 1$ can strongly influence the way he/she habitually handles words both in the L1 and in an L2, and the implications of this view for teaching English as a second language are discussed.

In a recent paper, Masterson, Coltheart and Meara (1985) reported a case of a native speaker of Spanish with unexpected dyslexic symptoms in English. That case raises some important issues for teachers of ESL, and the purpose of this paper is to bring these implications to the attention of people working in the profession. The paper is organised into two sections. Part one summarizes the clinical data from the case. Part two discusses the implications of the case in some detail.

\section{PART ONE}

FE is a native Spanish speaker, born in 1953 in Colombia, South America, who came to study in the UK at the age of 18. His family background is middle class, and he has no history of birth trauma, physical illness, or any form of delayed mental development. He does, however, have severe difficulty with English spelling, and in 1981, he approached his doctor about this problem, because it was feared that his poor spelling might prevent him from passing his final examinations.

Subsequent tests (administered in English) showed that he was of "superior" intelligence (an IQ of 125 on the Raven tests; Raven 1977). A small discrepancy was found between his scores on verbal and non-verbal tests (the latter were higher), and he also showed a slight short term memory deficit in that his ability to remember strings of digits is rather less than it ought to be. Both these deficits would be expected in an L2 speaker, however. 
A series of screening tests were administered to $\mathrm{FE}$ in English in order to test for signs of dyslexia. These tests are summarized below:

a) reading aloud regular and irregular words in English.

English words can be divided into two broad categories: those where the pronunciation can be determined by the application of a set of rules which relate spelling to pronunciation (regular words), and a set of irregular words whose pronunciation is basically idiosyncratic and unpredictable unless you know the word. FE made a total of 21 errors on a standard list of 78 words, with twice as many errors on irregular words as on regular ones.

b) spelling to dictation.

FE made 51 errors out of 100 on the Schonell Spelling Test, (Schonell 1966) but the majority of these errors were phonological (e.g., SERCH for SEARCH, COFF for COUGH, and HIGHDROLIC for HYDRAULIC.)

c) comprehension of written homophones.

Homophones are words that sound identical to each other, but are spelled differently (e.g., BEECH and BEACH, MEET and MEAT, etc.). FE's ability to handle these pairs was tested by reading aloud to him a definition of one member of a pair. He was then required to choose the correct answer from a set of four words: the two homophones and two controlled distractor words. FE made 41 errors on a list of 100 words, and a significant proportion of these errors consisted of his choosing the wrong member of the homophone pair.

These results suggest that, with respect to English, at least, FE shows some of the classic symptoms of developmental dyslexia, i.e. a dyslexia which is not due to traumatic brain injury. $\mathrm{He}$ is of above average intelligence; there is no evidence of neurological abnormality; his spoken English is adequate in every respect, but both reading and spelling are impaired. More specifically, the diagnostic tests suggest that the source of FE's difficulty is that he relies too heavily on a strategy of recoding the written forms of words into phonologically coded strings. This phenomenon is one of the central features of the type of dyslexia known as SURFACE DYSLEXIA (Marshall and Newcombe, 1973; Coltheart, Masterson, Byng, Prior \& Riddoch, 1983; Patterson, Marshall \& Coltheart, 1985).

The interesting question which arises at this stage, is whether FE is also a surface dyslexic in Spanish. This question is not as easy to answer as it might seem, however. Because the symptoms which are characteristic of 
this type of dyslexia rely on a severe mismatch between a language's orthography and its phonology, surface dyslexia is only really apparent in languages like English, Danish or French which have irregular orthographies. In languages with regular orthographies, homophones and irregular words do not exist, and this means that is is theoretically possible for someone to be a surface dyslexic without this disability ever becoming apparent. The skills that English speakers develop to handle irregular words and homophones are simply not needed in these languages. Spanish, unlike English, has an orthography that is very regular, but not entirely so. Some of the tests used to screen for surface dyslexia in English can also be constructed for Spanish. There are a few instances of sounds that can be spelled in two ways, for example, and this means that one can (with some ingenuity) construct a test similar to the homophone test in English-the irregular words test cannot be duplicated however.

FE's performance in Spanish is generally much better than it is in English. He correctly read aloud a list of 78 Spanish words; he made only 3 errors in reading aloud a passage of 500 words; and he misread only 3 out of 74 legal nonwords in Spanish (legal nonwords are sequences of letters which could belong to the language in question but just happen not to exist.) However, his spelling of dictated words was poor (14 out of 24 correct), again with a preponderance of phonologically correct mispellings. He also produced a very high proportion of errors on the Spanish homophone test ( 24 out of 40 ). These results suggest that FE has little difficulty in handling written words in Spanish, except where there is no simple direct mapping of graphemes and phonemes. In other words, he shows essentially the same symptoms in English and Spanish, but his overall performance reflects the fact that Spanish orthography is regular in almost all everyday situations.

To be fair, we ought to point out that there are a number of other possible explanations of FE's behaviour which do not rely on a diagnosis of dyslexia. One possibility is that $\mathrm{FE}$ is simply behaving in a way that would be typical of a younger, non-dyslexic reader. Specifically, good readers in the early stages of learning to read make more errors on exceptions than on regular words, and the spelling errors made by good spellers tend to be phonological. Another alternative is that FE is not dyslexic, but rather an extreme case of what Baron and Strawson (1976) have called "Phoenicians." These are individuals who rely heavily on spelling-sound correspondence rules, and whose reading behaviour is characterised by a tendency to read regular words well, but to misread exceptional words. Baron and Strawson contrast these readers with "Chinese" readers, i.e., readers who rely on word-specific associations, and can therefore read regular and irregular words well as long as they are familiar, but cope badly with any unfamiliar word. Some reasons for 
rejecting these alternative explanations will be found in Masterson, Coltheart and Meara (1985). Even if these arguments are wrong, however, they should not affect the argument put forward in part 2.

\section{PART TWO}

In order to see why FE's case is an important one for teachers of English as a second language, we first need a model which will allow us to explain how his behaviour differs from what we would expect in normal readers. A model of this sort is shown in Figure 1.

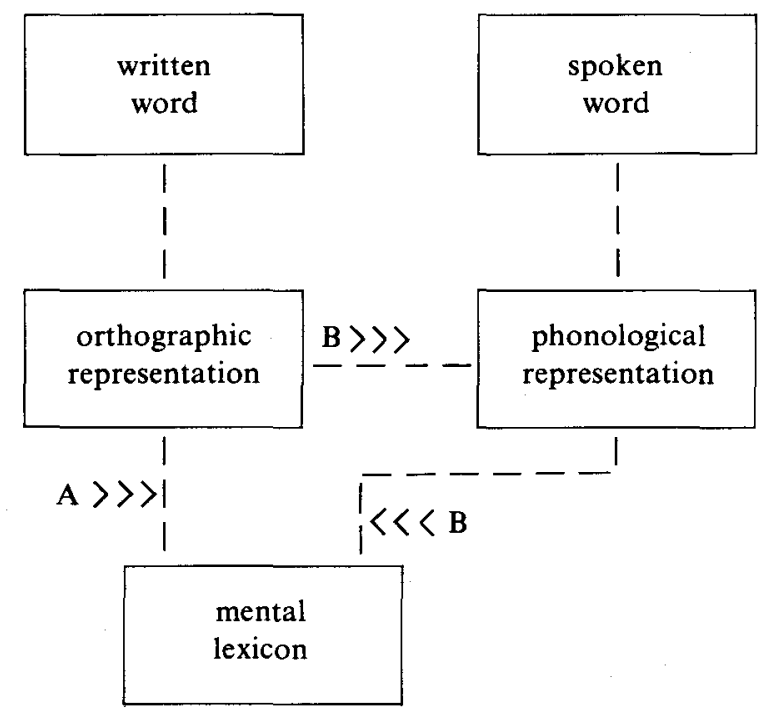

Figure 1. A schematic model of the recognition of written words.

According to this model, there are two ways of recognizing written words. The first route (A in Figure 1) is known as the DIRECT LEXICAL ACCESS route. When this route is employed, the surface phonological form of the word being processed plays no role at all. Recognition of the printed form is based purely on orthographic characteristics. The second route (B in Figure 1) is more complicated. In this case, the orthographic form of the word to be recognized is first converted into a phonological representation. Access to the mental lexicon is then achieved through these mediating phonological representations, just as it would be if the word were a spoken one.

One possible explanation of the behaviour of surface dyslexics (or "Phoenicians," or beginning readers) is that route A-the Direct Lexical 
Access route-is not available to them. Such readers rely almost entirely on the alternative phonologically mediated route. They are thus unable to read irregular words correctly because these are the very cases where there is no clear link between spelling and pronunciation. They fail to distinguish homophones because the phonological representations of homophones are identical. On the other hand, these readers can handle legal non-words easily because the regular nature of these words means that their phonological representations are accurate. The model therefore suggests that word recognition in these readers looks something like the model shown in Figure 2.

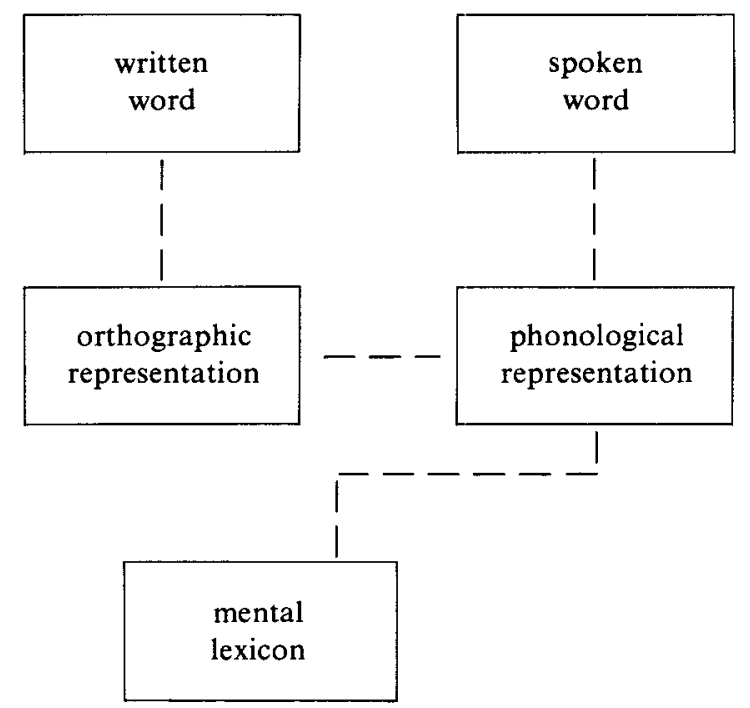

Figure 2. A schematic model of the recognition of written words by surface dyslexics, "Phoenicians" and beginning readers.

Clearly, a word recognition system such as that shown in Figure 2 will be severely deficient when it comes to operate in English. However, it is not obvious that this model would lead to any real handicap if one were operating in a language which had only a few irregular words. In a language like Italian or Finnish, where irregular words and homophones are practically non-existent, it would be perfectly possible for someone to be a surface dyslexic, (or a chronic "Phoenician" or a child-like reader) but for this fact never to be observed, or ever to intrude on his daily life. This seems to be very much the case with $\mathrm{FE}$, whose difficulties with written language become apparent only when he is required to operate in English.

This discussion has two main implications for ESL teachers. Firstly, 
many of the world's languages have orthographies that are regular and systematic, and differ from English in this respect. Now, whatever the causes of reading difficulties we found in FE, it seems reasonable to guess that the incidence of severe reading problems of this type among speakers of, say, Spanish, will be about the same as it is for native English speakers. Most of these cases will, however, remain undetected, for the reasons outlined above. If any of these people attempt to learn English, however, they are likely to meet with severe difficulties of a kind which are apparently unexplainable. Their spoken English will be fine, but their ability to cope with written English will be surprisingly poor, even dramatically bad. It would clearly be an exaggeration to suggest that this problem is a massive one, but when one considers the many millions of people learning English throughout the world, it is obvious that the chances of any individual teacher coming across at least one case like FE must be relatively high. It seems important to us that teachers should be able to recognize such cases when they arise.

Ironically, some modern teaching methods actually make the detection of such cases less likely. In many ESL programs, learners in the early stages of learning language are given a heavy exposure to the spoken word, and only limited exposure to the written form of the language. This means that a learner like FE can progress a long way before anyone realizes that he has a problem of any sort. When this happens, the subsequent realization that he cannot cope with written language can be very disturbing.

A second issue raised by this discussion is a rather more general one. It is commonly assumed in the psycholinguistic literature that the "natural" word recognition mechanism is that to be found in the model shown in Figure 1, where access to the lexicon can take place either via the direct route or via the phonologically mediated route. On consideration, however, it is not really obvious that this model is the natural one at all. Consider Spanish again. Spanish, as we have already seen, is a language with an almost entirely regular orthography. This means that there is no real need for Spanish speakers to develop a direct lexical access route. For all practical purposes, a model like that shown in Figure 2 will function adequately and economically for Spanish, and it could be argued that a direct lexical access route is a superfluous luxury, both unnecessary and inefficient. This argument suggests that FE's case is perhaps less peculiar than it appears to be at first sight. If phonologically mediated access works well for native speakers of Spanish, then maybe large numbers of native Spanish speakers will normally fail to develop the full model shown in Figure 1. The same sort of argument would also apply to native speakers of other regular languages as well. For all these speakers, the normal form of development could possibly correspond to the model 
shown in Figure 2. Experimental evidence which suggests that this is indeed the case among speakers of Serbo-Croat which is also a regular language, can be found in Feldman and Turvey (1983).

The practical consequences of accepting this argument are difficult to assess. One implication is that we may have been severely underestimating the difficulties facing speakers of Spanish and similar languages when they begin to learn English. Generally, we assume that people who are literate in one language can transfer their skills to another language with only minimal difficulty. It now looks as though this assumption needs to be called into question. For many learners, learning to read English may involve far more than the transfer of existing skills. Even when the learner's native language is quite similar to English in that it uses the Roman alphabet, learning to handle English words may involve a fundamental restructuring of the way the brain handles sequences of letters.

Where the learner's L1 does not use the Roman alphabet, the situation becomes even more complicated. The word recognition model shown in Figure 2 will certainly not work for Chinese speakers, for example, where the written forms of words have almost no relationship with their spoken forms. It also seems unlikely that Figure 2 will work for speakers of Arabic and Hebrew, where the written form of a word does not usually contain information about the pronunciation of the vowels. In these cases, too, and in others like them, learning to recognize words in English will involve large-scale restructuring of the mechanisms of word recognition, and this restructuring will be quite different in kind from the sort of restructuring that is necessary in a speaker of Spanish or Italian. How such restructuring takes place, or what we could do to help it take place efficiently and smoothly, are two questions for which there are currently no answers.

It has become rather fashionable recently for people to point out how very little we know about how words in a second language become integrated into learners' mental lexicons. FE's case suggests that we actually know even less about it than we thought we did.

\section{REFERENCES}

Baron, J. \& Strawson, C. (1976). Use of orthographic and word-specific knowledge in reading words aloud. Journal of Experimental Psychology: Human Perception and Performance, 2, 386-393.

Coltheart, M., Masterson, J., Byng, S., Prior, M. \& Riddoch, J. (1983). Surface dyslexia. Quarterly Journal of Experimental Psychology, 35a, 469-495.

Feldman, L.B. \& Turvey, M.T. (1983). Word recognition in Serbo-Croatian is phonologically analytic. Journal of Experimental Psychology: Human Perception and Performance, $9(2) 288-298$. 
Masterson, J., Coltheart, M. \& Meara, P. (1985). Surface dyslexia in a language without irregularly-spelled words. In K. Patterson, J.C. Marshall \& M. Coltheart (Eds.), Surface dyslexia: Cognitive and neuralogical studies of phonological reading. London: Lawrence Erlbaum Associates.

Marshall, J. \& Newcombe, F. (1973). Patterns of paralexia: a psycholinguistic approach. Journal of Psycholinguistic Research, 2, 175-199.

Patterson, K., Marshall, J.C. \& Coltheart, M. (Eds.) (1985). Surface dyslexia: Cognitive and neurological studies of phonological reading. London: Lawrence Erlbaum Associates.

Raven, J.C. (1977). Standard Progressive Matrices. Slough: National Foundation for Educational Research.

Schonell, F.J. (1966). The psychology and teaching of reading. London: Oliver and Boyd.

\section{THE AUTHORS}

Paul Meara is lecturer in the Department of Applied Linguistics at Birkbeck College, London University. He directs a program of research on Vocabulary Acquisition in foreign language learners. Max Coltheart is Professor of Psychology at Birkbeck College, London University, and is currently working on dyslexia. Jackie Masterson is a Research Assistant in the same department. She is currently working on dyslexia in Italian speakers. 